\title{
Nanograin layer formation at crack initiation region for very-high-cycle fatigue of a Ti-6Al-4V alloy
}

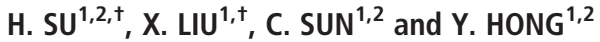 \\ ${ }^{1}$ LNM, Institute of Mechanics, Chinese Academy of Sciences, Beijing, China, ${ }^{2}$ University of Chinese Academy of Sciences, Beijing, China \\ Received Date: 15 August 2016; Accepted Date: 11 November 2016; Published Online: 7 December 2016
}

A B S TRACT The microstructural features and the fatigue propensities of interior crack initiation
region for very-high-cycle fatigue (VHCF) of a Ti-6Al-4V alloy were investigated in this
paper. Fatigue tests under different stress ratios of $R=-1,-0.5,-0.1,0.1$ and 0.5 were
conducted by ultrasonic axial cycling. The observations by SEM showed that the crack
initiation of VHCF presents a fish-eye (FiE) morphology containing a rough area
(RA), and the FiE and RA are regarded as the characteristic regions for crack initiation
of VHCF. Further examinations by TEM revealed that a layer of nanograins exists in
the RA for the case of $R=-1$, while nanograins do not appear in the FiE outside RA
for the case of $R=-1$, and in the RA for the case of $R=0.5$, which is explained by the
Numerous Cyclic Pressing model. In addition, the estimations of the fatigue propensities
for interior crack initiation stage of VHCF indicated that the fatigue life consumed by
RA takes a dominant part of the total fatigue life and the related crack propagation rate
is rather slow.

Keywords crack initiation; fatigue life; nanograins; Ti-6Al-4V alloy; very-high-cycle fatigue.

NOMENCLATURE

$2 a_{\mathrm{FiE}}=$ equivalent diameter of $\mathrm{FiE}$

$2 a_{\mathrm{RA}}=$ equivalent diameter of RA

$\sqrt{\text { area }}=$ equivalent size of $\mathrm{FiE}$ or $\mathrm{RA}$

$A, m=$ material parameters

$\mathrm{BFI}=$ bright field image

BSE = back scattered electron (imaging)

$\mathrm{EG}=$ equiaxed $\alpha$ grain

$\mathrm{FIB}=$ focused ion beam

$\mathrm{FiE}=$ fish-eye

FGA = fine granular area

HAADF = high angle annular dark field (imaging)

$\Delta K_{\mathrm{FiE}}=$ range of SIF in FiE region

$\Delta K_{\mathrm{RA}}=$ range of SIF in $\mathrm{RA}$

$\Delta K_{\mathrm{th}}=$ threshold of SIF

$\mathrm{LM}=$ lamellar structure

$\mathrm{NCP}=$ numerous cyclic pressing

$\mathrm{NG}=$ nanograin

$N_{\mathrm{f}}=$ total fatigue life

$N_{\mathrm{i}}=$ fatigue life of crack initiation

$\mathrm{RA}=$ rough area

$\mathrm{SAD}=$ selected (electron) area diffraction

SIF $=$ stress intensity factor

$\mathrm{VHCF}=$ very-high-cycle fatigue

Correspondence: Y. Hong. E-mail: hongys@imech.ac.cn

${ }^{\dagger}$ These authors contribute equally to this paper. 


$$
\begin{aligned}
Y & =\text { crack shape factor } \\
\sigma_{\mathrm{a}} & =\text { applied stress amplitude } \\
\sigma_{\text {eff }} & =\text { effective stress }
\end{aligned}
$$

\section{INTRODUCTION}

The research topic of very-high-cycle fatigue (VHCF) has attracted increasing interests for the demanding of fatigue design in engineering applications and for the request of understanding the related fatigue failure mechanism. ${ }^{1-5}$ With the development of engineering technology and the requirement of natural resource conservation, many structural components such as highspeed train axles ${ }^{6,7}$ and aircraft structures ${ }^{8}$ are designed to bear the fatigue life of more than $10^{7}$ cycles, which booms the investigation on VHCF. It has been known that a fatigue crack always initiates from the interior of specimen for $\mathrm{VHCF},{ }^{9,10}$ which is different from the surface crack initiation mechanism for low-cycle fatigue and high-cycle fatigue. ${ }^{11,12}$ In addition, the unique influences of stress ratio, ${ }^{13-15}$ strength level, ${ }^{16}$ loading frequency, ${ }^{16,17}$ specimen size ${ }^{18,19}$ and environmental condition $^{20,21}$ on the behavior of VHCF have been reported. However, the theories of physics and mechanics for the explanation of VHCF experiments still need further development.

For the VHCF behavior of titanium alloys, the S-N curves often present a step-wise shape, and the fatigue strength has a sharp decrease at the fatigue life between $10^{7}$ and $10^{9}$ cycles. ${ }^{17,22,23}$ The typical pattern of interior crack initiation region exhibits a pattern of fish-eye (FiE) and rough area (RA) with facets distributed randomly. ${ }^{24,25} \mathrm{RA}$ is the region of crack initiation for VHCF of titanium alloys ${ }^{24,25}$ and the mechanism of crack initiation at RA is because of the cleavage of primary $\alpha$ grains at the beginning and then the coalescence of the originated cracks (facets). ${ }^{26}$

For high strength steels, the morphology of crack initiation for VHCF is typically a FiE containing a RA, which is called fine granular area (FGA) ${ }^{27,28}$ and is regarded as the characteristic region ${ }^{29}$ for VHCF. The formation process of FGA is so important that it consumes more than $95 \%$ of total fatigue life. ${ }^{29,30}$ Thus, it received a number of investigations with different explanations for its formation mechanism, including 'hydrogen assisted crack growth', 31,32 'decohesion of spherical carbides', ${ }^{33}$ 'formation and debonding of fine granular layer', ${ }^{27,34}$ 'local grain refinement at crack tip and debonding', ${ }^{35}$ and 'vortical plastic flows to produce nanostructure layer and debonding. ${ }^{36}$ These proposed mechanisms encountered difficulties in the explanation of different experimental cases including a recent result ${ }^{37}$ for a martensitic $12 \% \mathrm{Cr}$ steel, for which the morphology of FGA was observed in the specimens at $R=-1$ but never found in the specimens fatigued at $R=0.1,0.5$ and 0.7 . Recently, it was revealed that this characteristic region of FGA is a nanograin (NG) layer of several hundred nanometer thick on both crack surfaces for the cases of negative stress ratios, while the NG layer diminishes for the cases of positive stress ratios. ${ }^{38}$ Then, the mechanism of numerous cyclic pressing (NCP) between originated crack surfaces was proposed to describe the formation process of FGA. ${ }^{38}$ For titanium alloys, the formation of RA was briefly explained by the process of cold-welding (re-bonding) because of the contacts between crack surfaces during cyclic loading, ${ }^{39}$ although the microstructure detail was not identified. More recently, the morphology of FiE and RA for crack interior initiation at VHCF regime for a titanium alloy was examined and the observations of grain refinement at crack initiation region by electron back-scattered diffraction gave the mean grain size in area down to $3.8 \mu \mathrm{m}^{2}$ for a VHCF case. ${ }^{40}$ Nevertheless, the detailed microstructure and the grain size just underneath the crack initiation region of VHCF for titanium alloys are not clearly understood, which needs in-depth investigation.

As known, for the VHCF of high-strength steels, the process of crack initiation and early propagation consumes more than $95 \%$ of the total fatigue life. ${ }^{29,30}$ The crack propagation rate in the crack initiation region was estimated as the order of magnitude between $10^{-12}$ and $10^{-13} \mathrm{~m} /$ cycle. $^{29,30}$ The stress intensity factor (SIF) range at the boundary of FGA and FiE keeps constant, ${ }^{29,41,42}$ and the SIF of FGA is comparable to the threshold value of fatigue crack initiation. However, the estimation of fatigue life and crack propagation rate in the VHCF for titanium alloys is rarely reported.

In this paper, a titanium alloy of $\mathrm{Ti}-6 \mathrm{Al}-4 \mathrm{~V}$ was used for the investigation on crack initiation behavior for VHCF. Fatigue tests under different stress ratios $(R=-1,-0.5,-0.1,0.1$ and 0.5$)$ were performed with an ultrasonic fatigue testing machine. The fractography of failed specimens in VHCF regime was examined by scanning electron microscopy (SEM), showing that the crack initiation region presents a FiE pattern embracing a RA. The microstructures of RA and FiE were observed by transmission electron microscopy (TEM) equipped with selected (electron) area diffraction (SAD) device. The results indicate that nanograins formed for the cases of negative stress ratios, but disappeared for the cases of positive stress ratios. Further, the formation of 
nanograins is attributed to the numerous cyclic pressing between the crack surfaces and crack closure by the previous proposed NCP model. In addition, the values of fatigue life from RA to the boundary of FiE and from the boundary of FiE to critical crack size were calculated, and the results were used to estimate the crack propagation rate within $\mathrm{RA}$.

\section{TEST MATERIAL AND EXPERIMENTAL PROCEDURE}

The test material in this research is an $\alpha-\beta$ titanium alloy (Ti-6Al-4V) with the chemical compositions (wt. \%): $5.8 \mathrm{Al}, 4.2 \mathrm{~V}, 0.12 \mathrm{Fe}, 0.03 \mathrm{~N}, 0.02 \mathrm{C}, 0.005 \mathrm{H}, 0.15 \mathrm{O}$ and balance Ti. Duplex microstructure consisting of equiaxed grains and lamellar domains was obtained by designed heat-treatments $\left(920^{\circ} \mathrm{C} / 1 \mathrm{~h}+\right.$ air-cooling and $550^{\circ} \mathrm{C} / 4 \mathrm{~h}+$ air-cooling). ${ }^{24}$ The volume fraction of $\alpha$ phase (hcp lattice), which is the sum of the primary $\alpha$ grains and the secondary $\alpha$ phase in lamellar domains, is $98.4 \%$, and that of $\beta$ phase (bcc lattice) distributed in lamellar domains is $1.6 \%$. The average diameter of the equiaxed $\alpha$ grains is $5.89 \mu \mathrm{m}$, and the width of the secondary $\alpha$ phase in the lamellar domains is about $1 \mu \mathrm{m}$. The yield strength and tensile strength of specimens were $812 \mathrm{MPa}$ and $945 \mathrm{MPa}$, respectively. The micro hardness was $310 \mathrm{Hv}$. The detailed information of the material was described elsewhere. ${ }^{24}$ Note that the heat treatment for the specimens to be tested at $R=-1$ is slightly different $\left(920^{\circ} \mathrm{C} / 8 \mathrm{~h}+\right.$ air-cooling and $550^{\circ} \mathrm{C} / 4 \mathrm{~h}+$ air-cooling).

The fatigue tests were conducted on an ultrasonic fatigue testing machine (equipped with a tensile machine) at a resonance frequency of $20 \mathrm{kHz}$ at room temperature in air and the mean stress can be adjusted so as to provide the capability of performing fatigue tests under different stress ratios of $R=-1,-0.5,-0.1,0.1$ and 0.5 . Hourglass shape specimens were used in the test, and the dimensions of specimens are shown in Fig. 1a and b. The fracture surfaces of all failed specimens were observed by using a field-emission type scanning electron microscope. Special attention was paid on the observations for the regions of $\mathrm{RA}$ and $\mathrm{FiE}$.

The characterization of microstructures in the regions of RA and FiE is the main concern of this paper, which is beyond traditional TEM preparation methods such as double shear thin electrolytic method. Focused ion beam (FIB) technique has excellent advantages on micro/nano positioning and avoiding any damage on the sample, which has been used in the TEM sample preparation in this paper. Four profile samples, that is, TEM samples, each with the size of length $10 \mu \mathrm{m}$, width $5 \mu \mathrm{m}$ and thickness $80 \mathrm{~nm}$, were cut from fracture surfaces of three failed specimens tested under different stress ratios via a HELIOS Nanolab 600i FIB device. Two TEM samples, A1-RA and A2-RA, were located in the RA region of Specimens A1 (blue point in Fig. 1c) and A2 (red point in Fig. 1c), and one TEM sample, A1-FiE, was located in the FiE region outside $\mathrm{RA}$ of Specimen $\mathrm{A} 1$. Note that the applied stress ratio for Specimens A1 and A2 was $R=-1.0$ (Fig. 1c). The fourth TEM sample, B1-RA, was located in the RA of Specimen B1 (purple point in Fig. 1c), which was subjected to the stress ratio of $R=0.5$ (Fig. 1c). A platinum ( $\mathrm{Pt}$ ) layer was coated on the selected fracture surfaces for preventing damages caused by the ejective ions during FIB processing. The profile samples were carefully examined via a TALOS F200X TEM equipped with SAD (diffraction (a)

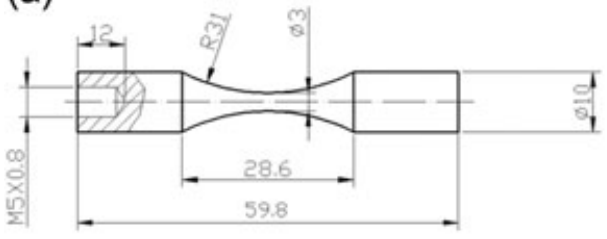

(b)

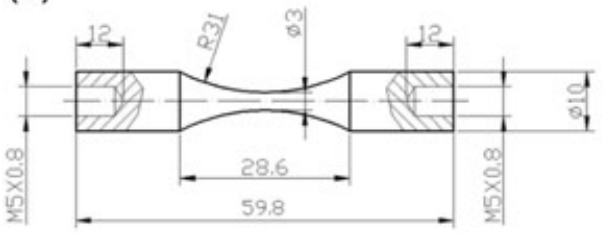

(c)

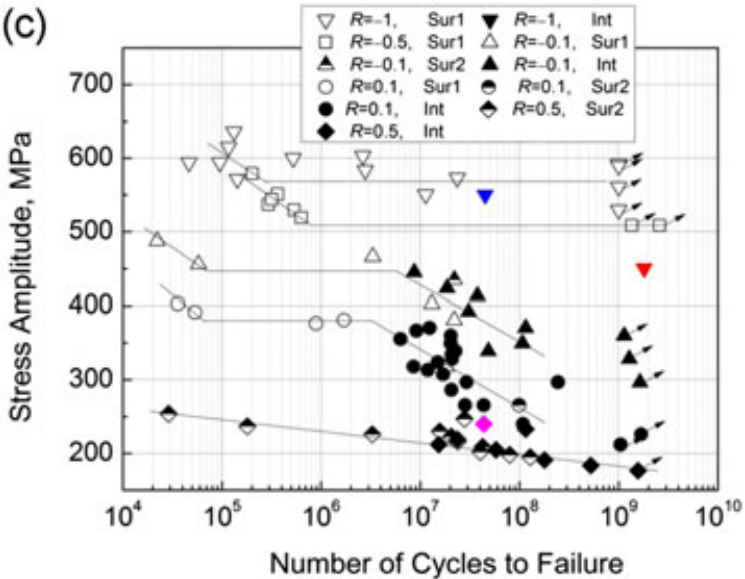

Fig. 1 Two types of specimens (dimensions in $\mathrm{mm}$ ) used in fatigue test and $\mathrm{S}-\mathrm{N}$ curves (data of $R=-0.5,-0.1,0.1$ and 0.5 from Ref. 24$),(\mathrm{a})$ ultrasonic axial cycling without mean stress, (b) ultrasonic axial cycling with superimposed mean stress, and (c) S-N curves in terms of applied stress amplitude, symbols with arrow: run out, Sur: surface crack initiation, Int: interior crack initiation, Blue point: Specimen A1, red point: Specimen A2, purple point: Specimen B1. [Colour figure can be viewed at wileyonlinelibrary.com] 
area of $250 \mathrm{~nm}$ in diameter) and with high angle annular dark field (HAADF) imaging. The fine grains in the crack initiation region were identified from the TEM images, and the size of such fine grains was readily measured.

\section{RESULTS AND DISCUSSION}

\section{Fractography and dimensions of RA and FiE}

Figure 2 presents the typical fracture surface of interior crack initiation region in VHCF for the tested Ti-6Al-4V. The whole region of crack initiation and early propagation exhibited a pattern of FiE (marked by the outer dashed circle in Fig. $2 \mathrm{a}$ and $\mathrm{b}$ ). The initiation region of RA was located generally at the center of the FiE. This type of fracture surface prevailed for all cases of positive and negative stress ratios, and was also reported in the literature. ${ }^{43,44}$ No inclusions were observed in the RA, which was different from the situation of an inclusion as crack origin for high-strength steels. $^{28-30}$

Here, RA and FiE are regarded as characteristic regions I and II, and the sizes of equivalent diameters for $\mathrm{RA}$ and $\mathrm{FiE}$ are regarded as characteristic dimensions I and II for crack initiation. The equivalent diameter is defined as the diameter of a circle, which takes the same area with the characteristic region. Figure 3 is presented to show the borders between different characteristic regions. The grey level of SEM image along with the crack propagation path helps to distinguish the borders between the regions (Fig. 3a). A high magnification image shown in Fig. 3b presents facet morphologies in $\mathrm{RA}$, which are the indicators of RA region and help to distinguish the border between RA and the rest of FiE, as no facets exist in FiE outside RA. Further, a so-called co-measurement method was applied to identify the borders. The co-measurement means multi observers participating in a measuring process, which efficiently cuts down the deviation of the RA dimensions to

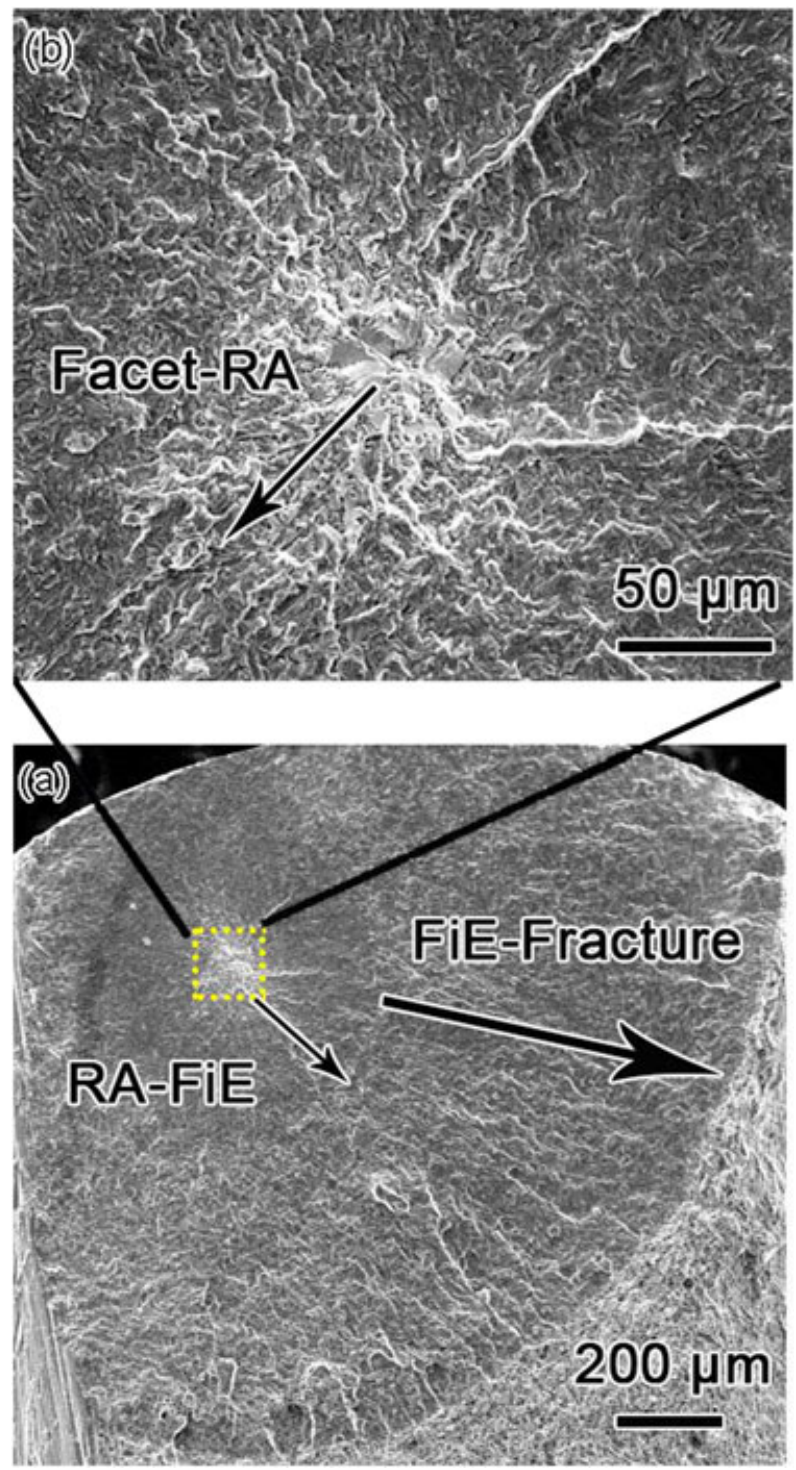

Fig. 3 Fracture surface of Ti-6Al-4V, $R=-0.1, \quad \sigma_{\mathrm{a}}=423.9 \mathrm{MPa}$, $N_{\mathrm{f}}=1.84 \times 10^{7}$, (a) SEM image showing three regions of facet-RA (RA containing facets), RA-FiE (RA to FiE border) and FiE-Fracture (FiE to fracture border), and (b) High magnification SEM image showing Facet-RA region. [Colour figure can be viewed at wileyonlinelibrary.com]

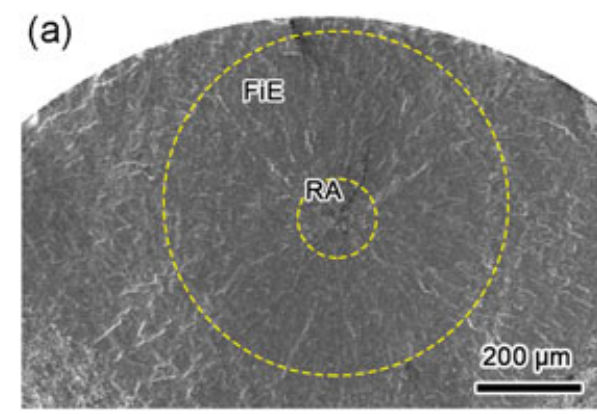

(b)

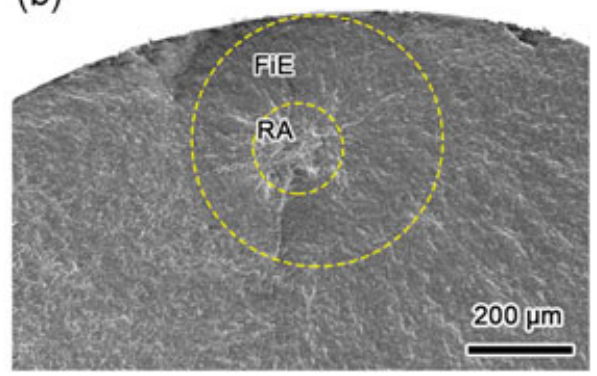

Fig. 2 SEM images showing typical interior crack initiation in VHCF regime of Ti-6Al-4V (FiE: fish-eye, RA: rough area), (a) $R=-1$, $\sigma=550 \mathrm{MPa}, N_{\mathrm{f}}=4.52 \times 10^{7}$, (b) $R=0.1, \sigma_{\mathrm{a}}=339 \mathrm{MPa}, N_{\mathrm{f}}=2.26 \times 10^{7}$. [Colour figure can be viewed at wileyonlinelibrary.com] 
Table 1 Measurement results of $2 a_{\mathrm{RA}}$ and $2 a_{\mathrm{FiE}}$ with the data of applied stress amplitude, effective stress and fatigue life for the cases of tested stress ratios

\begin{tabular}{lllllr}
\hline$R$ & \multicolumn{1}{c}{$N_{\mathrm{f}}$} & $\begin{array}{c}\sigma_{\mathrm{a}} \\
(\mathrm{MPa})\end{array}$ & $\begin{array}{c}\sigma_{\mathrm{eff}} \\
(\mathrm{MPa})\end{array}$ & $\begin{array}{c}2 a_{\mathrm{RA}} \\
(\mu \mathrm{m})\end{array}$ & $\begin{array}{r}2 a_{\mathrm{FiE}} \\
(\mu \mathrm{m})\end{array}$ \\
\hline-1 & $1.8 \times 10^{9}$ & 450 & 450 & 251 & 1400 \\
-1 & $4.5 \times 10^{7}$ & 550 & 550 & 139 & 1254 \\
-0.1 & $1.8 \times 10^{7}$ & 423.9 & 771 & 129 & 615 \\
-0.1 & $3.8 \times 10^{7}$ & 413.25 & 751 & 170 & 362 \\
-0.1 & $3.1 \times 10^{7}$ & 392.25 & 713 & 158 & 1073 \\
-0.1 & $1.2 \times 10^{8}$ & 370.5 & 674 & 168 & 599 \\
0.1 & $1.2 \times 10^{7}$ & 370.5 & 741 & 117 & 1129 \\
0.1 & $2.0 \times 10^{7}$ & 349.5 & 699 & 147 & 1311 \\
0.1 & $6.3 \times 10^{6}$ & 355.5 & 711 & 155 & 1388 \\
0.1 & $2.3 \times 10^{7}$ & 339 & 678 & 184 & 518 \\
0.1 & $2.4 \times 10^{8}$ & 297 & 594 & 212 & 521 \\
0.1 & $1.5 \times 10^{7}$ & 324 & 648 & 178 & 585 \\
0.1 & $1.2 \times 10^{7}$ & 313.5 & 627 & 163 & 900 \\
0.1 & $4.3 \times 10^{7}$ & 265.5 & 531 & 187 & 954 \\
0.1 & $2.8 \times 10^{7}$ & 265.5 & 531 & 199 & 761 \\
0.5 & $4.3 \times 10^{7}$ & 240 & 480 & 143 & 1182 \\
0.5 & $1.5 \times 10^{7}$ & 212 & 424 & 276 & 937 \\
0.5 & $1.8 \times 10^{8}$ & 191 & 382 & 335 & 788 \\
0.5 & $5.2 \times 10^{8}$ & 183.7 & 367 & 392 & 1132 \\
\hline
\end{tabular}

approximate $10 \%$. Consequently, the sizes of equivalent diameters $\left(2 a_{\mathrm{RA}}\right.$ and $\left.2 a_{\mathrm{FiE}}\right)$ were measured from SEM images.

Table 1 lists the measured data of $2 a_{\mathrm{RA}}$ and $2 a_{\mathrm{FiE}}$ for the cases of tested stress ratios together with the values of related applied stress amplitude $\left(\sigma_{\mathrm{a}}\right)$, effective stress $\left(\sigma_{\text {eff }}\right)$ and fatigue life $\left(N_{\mathrm{f}}\right)$. Note that the effective stress is the stress range for $R \geq 0$ or the maximum stress for $R<0$, so that the effect of stress ratio is included. The values of $2 a_{\mathrm{RA}}$ and $2 a_{\mathrm{FiE}}$ in Table 1 are plotted in Fig. $4 \mathrm{a}$, which presents the relationship between the characteristic region sizes and the effective stresses. This result indicates that a large size of RA does not always match a large size of FiE. The size of RA seems to increase with the increase of stress ratio, while the size of FiE is insensitive to the value of stress ratio.

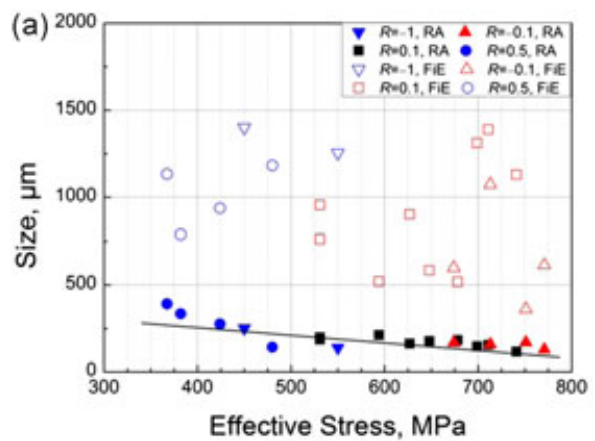

It is shown in Table 1 and Fig. 4a that the size of FiE scatters in a large range from 362 to $1400 \mu \mathrm{m}$ independent of the effective stress, and that of RA is distributed in a relative small range between 117 and $392 \mu \mathrm{m}$ decreasing with the increase of the value of effective stress. This result implies that compared with FiE, the size of RA is a more representative dimension with regard to the crack initiation for VHCF of the titanium alloy.

For the sake of analysis and discussion, the interior crack initiation sites are treated as concentric penny cracks, and then, the values of stress intensity factor range (SIF) at the boundary of FiE $\left(\Delta K_{\mathrm{FiE}}\right)$ and $\mathrm{RA}\left(\Delta K_{\mathrm{RA}}\right)$ are calculated by using the following equation: ${ }^{45}$

$\Delta K=0.5 \sigma_{e \text { ff }} \sqrt{\pi \sqrt{\text { area }}}$

where $\sigma_{\text {eff }}$ is the effective stress, which takes the value of the stress range for $R \geq 0$ or the maximum stress for $R<0$, and $\sqrt{\text { area }}$ is the equivalent size of $\mathrm{FiE}$ or $\mathrm{RA}$. It is noteworthy that the method of Eq. (1) has been used in many other papers, e.g. Refs. 13, 14, 24, 29, 31, 32 and 42. The results are plotted as a function of fatigue life as shown in Fig. $4 \mathrm{~b}$. It is seen that the values of $\Delta K_{\mathrm{FiE}}$ scattering in the range of $10-25 \mathrm{MPa} \cdot \mathrm{m}^{1 / 2}$, while the values of $\Delta K_{\mathrm{RA}}$ are within a small range of $6.2-8.69 \mathrm{MPa} \cdot \mathrm{m}^{1 / 2}$ regardless of fatigue life and stress ratio. The mean value of $\Delta K_{\mathrm{RA}}$ is $7.0 \mathrm{MPa} \cdot \mathrm{m}^{1 / 2}$, which approximates to the threshold of the effective stress intensity factor range for crack growth $\left(7.1 \mathrm{MPa} \cdot \mathrm{m}^{1 / 2}\right)$ in vacuum. ${ }^{39}$

\section{NG layer formation in RA for the case of $R=-1$}

Figure 5 presents the TEM observations with SAD results on the sample of A1-RA cut from RA region for the case of $R=-1$. Figure 5a is the SEM image that shows the RA region (dotted curve loop) where a FIB sample was cut (marked by a rectangle in Fig. 5a). Then, the profile morphology of the FIB sample was carefully examined by TEM, and the image was shown in Fig. 5b,

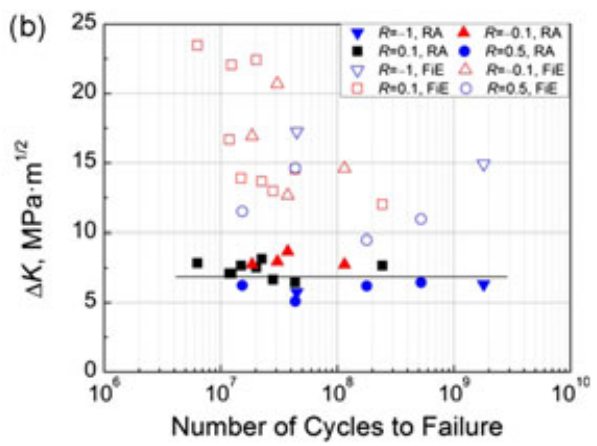

Fig. 4 (a) Sizes of RA and FiE versus effective stress for the cases of tested stress ratios, and (b) $\Delta K$ of RA and FiE as a function of fatigue life for the cases of tested stress ratios. [Colour figure can be viewed at wileyonlinelibrary.com] 


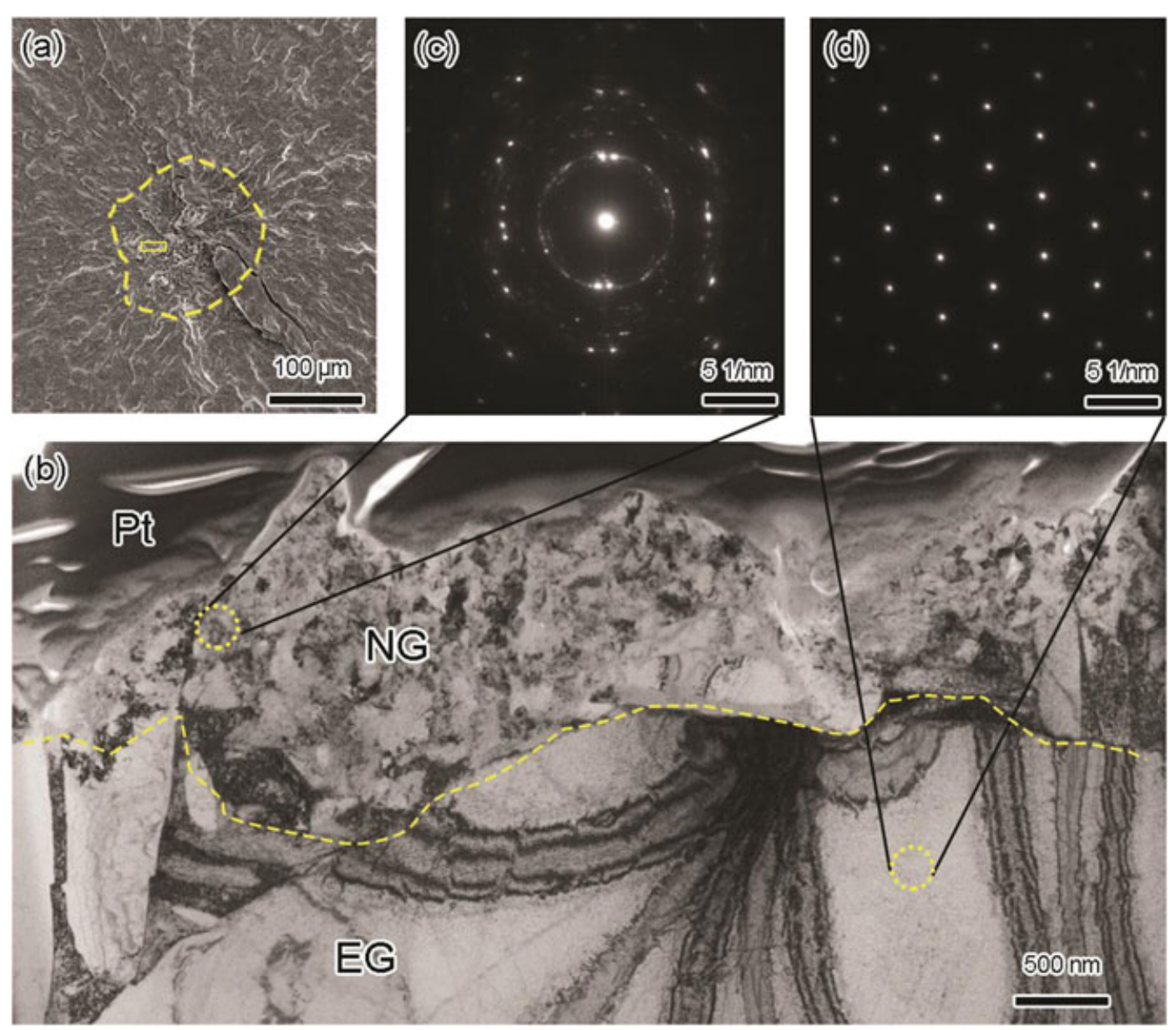

Fig. 5 Microstructure characterization of RA profile for A1-RA: (a) Fracture surface of specimen A1 with $R=-1, \sigma_{\mathrm{a}}=550 \mathrm{MPa}, N_{\mathrm{f}}=4.52 \times 10^{7}$, (b) BFI showing three layers in the profile, that is, Pt layer, NG layer and EG layer, (c) SAD pattern at a location just underneath RA surface, showing discontinuous diffraction circles indicating several grains within the selected area, and (d) SAD pattern at a location about $2 \mu \mathrm{m}$ away from RA surface showing isolated diffraction spots of a single grain feature. [Colour figure can be viewed at wileyonlinelibrary.com]

which contains three layers, namely a $\mathrm{Pt}$ coating layer $(\mathrm{Pt})$, a NG layer and an equiaxed $\alpha$ grain layer (EG). The Pt layer plays the role of protection, the NG layer is of a thickness of $800-1500 \mathrm{~nm}$ underneath the RA surface, and the EG layer is the original microstructure of equiaxed $\alpha$ grains. SAD examinations were conducted on the NG layer and the EG layer with the results as shown in Fig. 5c and d, respectively. For the NG layer, the SAD pattern of Fig. 5c shows discontinuous diffraction circles, suggesting that several grains exist within the diffraction area of $250 \mathrm{~nm}$ in diameter. Whereas for the EG layer, the pattern of isolated spots appears in the SAD image (Fig. 5d), which is a normal diffraction of a single grain. Therefore, we can infer that a layer of nanograins formed in the RA from original equiaxed $\alpha$ grains. Away from this narrow layer of nanograins, the microstructure is of the feature of equiaxed $\alpha$ grains.

This result reveals that the grain refinement or the nanograin formation really exists during the process of
VHCF in RA, where a predominant part of the total fatigue life is consumed. This is comparable with the results for the case of high-strength steels. ${ }^{38} \mathrm{~A}$ second TEM sample (A2-RA) was cut by FIB also from the case of $R=-1$. This sample was again examined by TEM and $\mathrm{SAD}$, so that to see if the NG layer underneath RA surface is a common phenomenon. Figure 6a shows the RA morphology and the location of FIB sampling. Similar results with Fig. 5 were obtained by TEM observations (Fig. 6b) and SAD patterns (Fig. 6c and d). Figure $6 \mathrm{~b}$ shows the presence of three layers of $\mathrm{Pt}, \mathrm{NG}$ and EG. The SAD pattern of Fig. 6c indicates the existence of nanograins underneath the RA surface and that of Fig. 6d shows the original microstructure of EG. The observations of Fig. 6 confirm that an NG layer of about $800-1500 \mathrm{~nm}$ exists underneath the RA surface for the case of $R=-1$ of VHCF for the tested titanium alloy. It is worth noting that the original microstructure for this case is lamellar structure (LM), which is different 

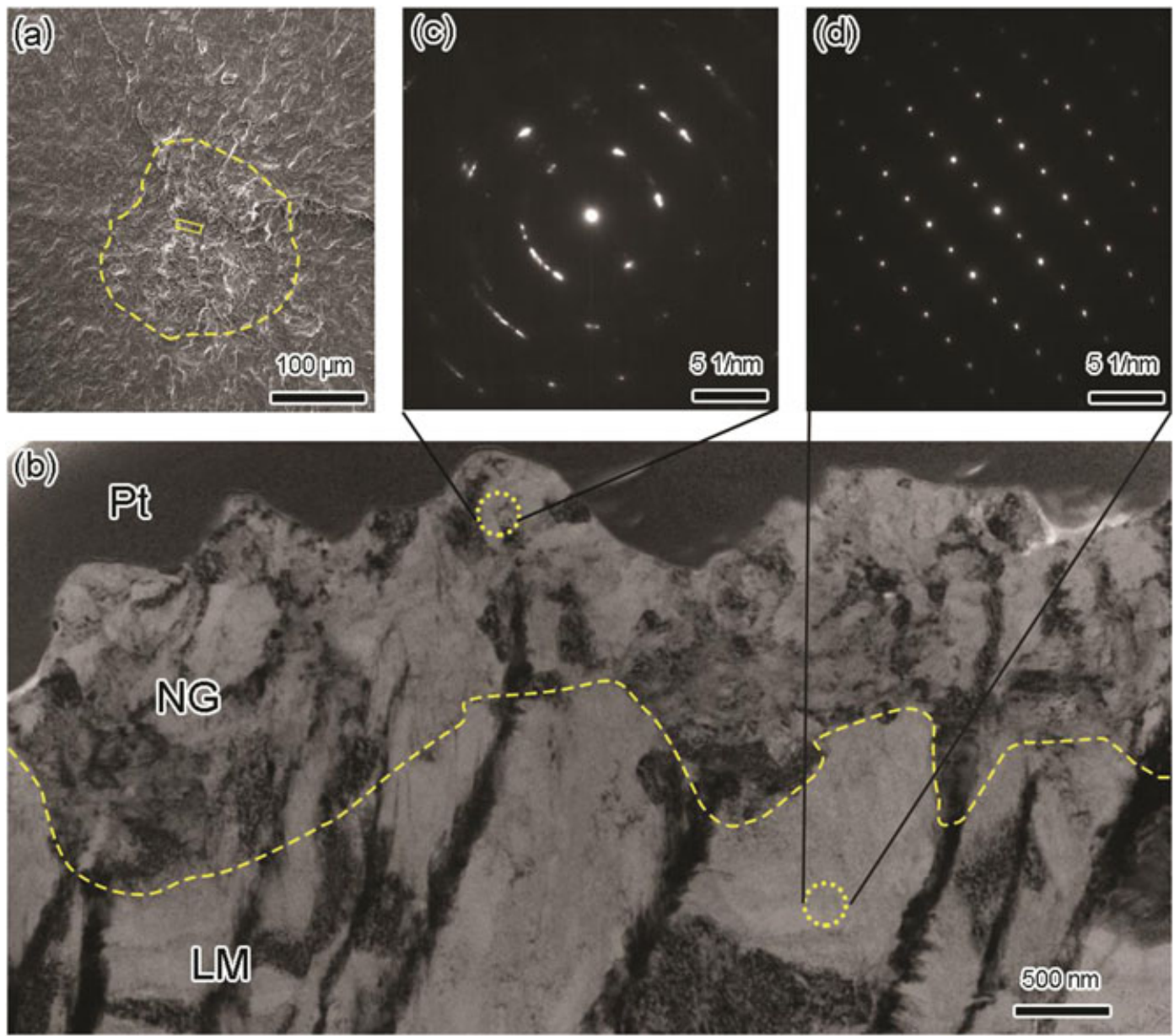

Fig. 6 Observations for the microstructure of RA for A2-RA: (a) Fracture surface of specimen A2 with $R=-1, \sigma_{\mathrm{a}}=450 \mathrm{MPa}, N_{\mathrm{f}}=1.79 \times 10^{9}$, showing RA (dotted curve loop) and location for TEM sample cutting by FIB (marked by a rectangle), (b) BFI, LM: lamellar microstructure, (c) SAD pattern underneath RA surface, (d) SAD pattern away from RA surface. [Colour figure can be viewed at wileyonlinelibrary.com]

from the case above (Fig. 5b) and thus suggests that both equiaxed and lamellar microstructures can form nanograins. Together with the results of nanograin layer formation in the FGA of high-strength steels ${ }^{38,46}$, we may presume that the type of microstructure is not a dominating factor to the process of nanograin formation during crack initiation of VHCF.

Figure $7 \mathrm{a}$ and $\mathrm{b}$ presents the high magnification bright field images (BFI) of the NG layer, showing a more distinct morphology of nanograins in the NG layer of A1-RA and A2-RA. The corresponding SAD patterns attached to Fig. 7a and b present discontinuous diffraction circles with the calibrated indexes conforming to a standard diffraction pattern of $\alpha$ phase (hcp lattice). It is interesting that all 15 except one of the calibrated indexes of discontinuous diffraction circles are hep diffraction of $\alpha$ phase, which is in accordance with the predominant volume fraction of $98.4 \%$ for $\alpha$ phase of this titanium alloy.
Subsequently, the grain sizes in NG layer were measured from the BFIs. The result was based on the measurements of 318 grains. Figure 7c shows the distribution of nanograin sizes, indicating that the nanograin sizes range from 60 to $160 \mathrm{~nm}$ with the average value of $105 \mathrm{~nm}$. The diameter of original equiaxed $\alpha$ grains is $5.89 \mu \mathrm{m}$ in average, and the average width of lamellar structure is about $1 \mu \mathrm{m}$. The microstructure evolution in the RA is a grain refinement process with the scale from micrometer to nanometer. It is also seen from Figs $5 \mathrm{~b}$ and $6 \mathrm{~b}$ that the nanograin cluster is more pronounced close to the RA surface and the refinement gradually diminishes towards the boundary between NG and EG. This is reflected by the measurements of nanograin size variation as a function of the distance away from RA surface as shown in Fig. 7d. It is evident that the size of nanograins increases with the increase of the distance away from RA surface, about $75 \mathrm{~nm}$ in the location of $0-250 \mathrm{~nm}$ from RA surface, $115 \mathrm{~nm}$ in the location of 

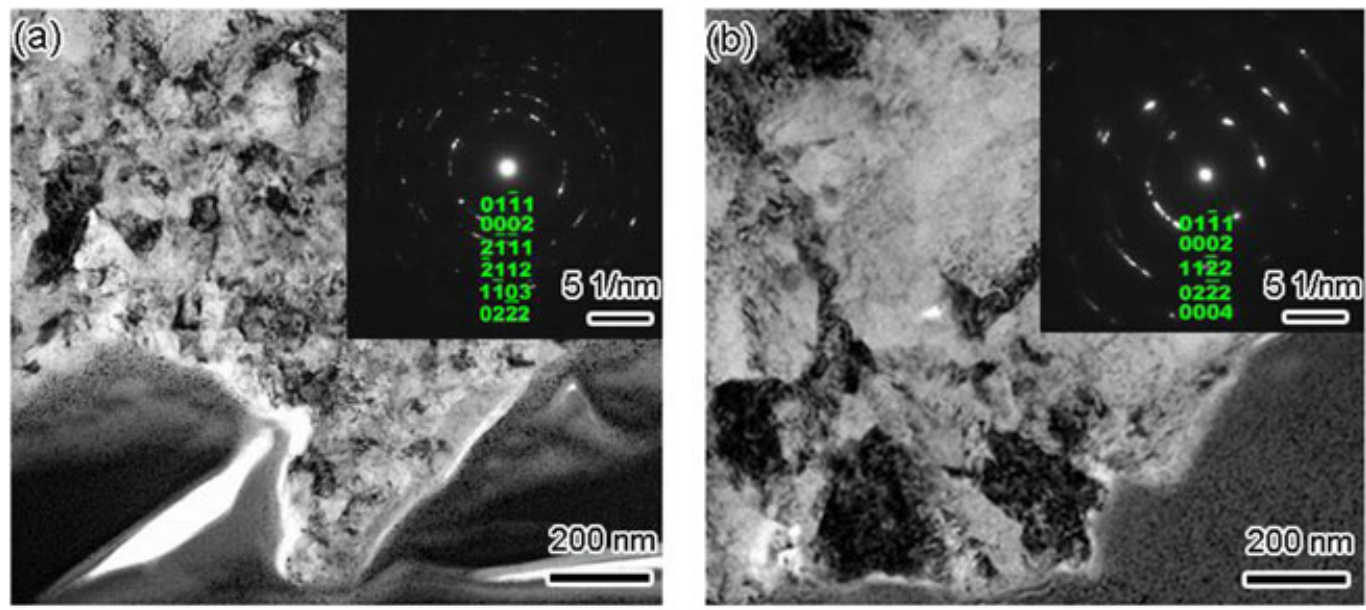

(c)
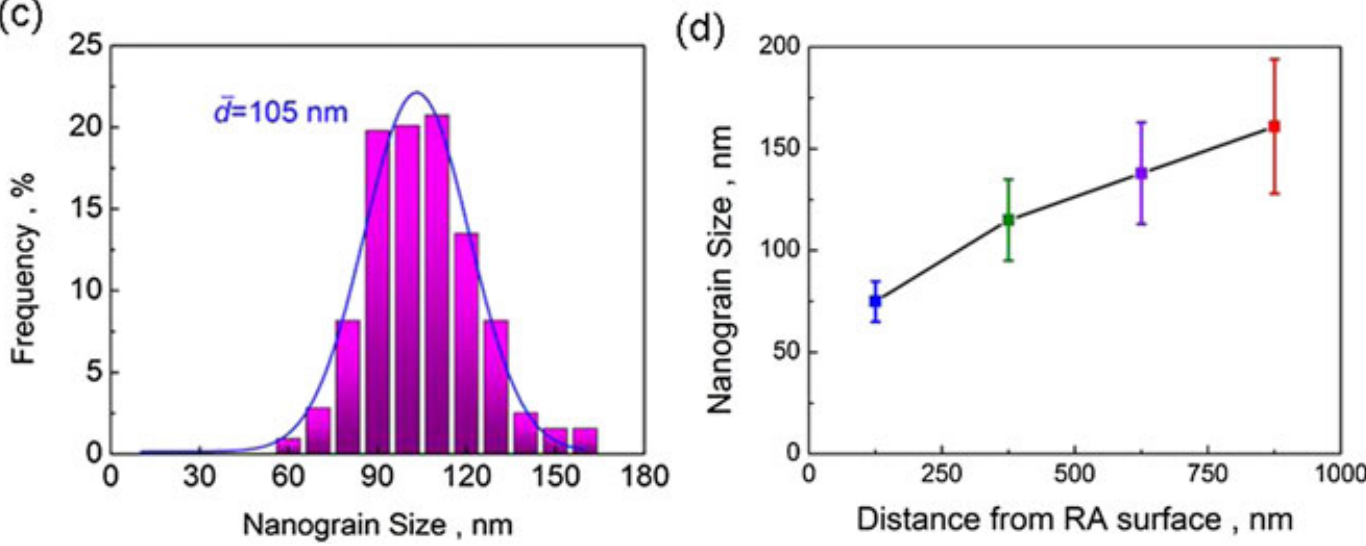

Fig. 7 High magnification images of NG layer and the distribution of grain sizes in NG layer. (a) BFI of A1-RA and related SAD detections with calibrated indexes, (b) BFI of A2-RA and related SAD detections with calibrated indexes, (c) nanograin size measurements with the average of 105 nanometers and (d) variation of nanograin size with the increase of distance away from RA surface. [Colour figure can be viewed at wileyonlinelibrary.com]

$250-500 \mathrm{~nm}$ from RA surface, $138 \mathrm{~nm}$ in the location of $500-750 \mathrm{~nm}$ from RA surface and $161 \mathrm{~nm}$ in the location of 750-1000 nm from RA surface. This observation result implies that during VHCF process, the microstructure underneath crack surfaces within RA experienced different evolution extents. The deformation of the microstructure just underneath the fracture surface was so severe that the grain refinement developed sufficiently in the local area. However, this kind of process weakened with the increase of the distance away from the fracture surface causing a gradient feature shown in Figs 5b, 6b and $7 \mathrm{~d}$, which is an interesting revelation comparable to the cases of high-strength steels. ${ }^{38}$

Without grain refinement in FiE outside RA for $R=-1$ and in RA for $R=0.5$

As mentioned above, nanograins are found in the samples A1-RA and A2-RA. Then, another TEM sample A1-FiE also from Specimen A1 located in the region of FiE but outside RA has been prepared as shown in Fig. 8a. It should be noted that A1-FiE was taken from the counterpart of fracture surface of Specimen A1 from which A1-RA was taken. BFI for the FiE region (Fig. 8b) shows that coarse grains prevailed, that is, no nanograins formed even just underneath the fracture surface. Figure $8 \mathrm{c}$ and $\mathrm{d}$ is the $\mathrm{SAD}$ patterns detected underneath the FiE (outside RA) surface. Both patterns of Fig. 8c and $\mathrm{d}$ show isolated spots, implying just one grain in the diffraction area, which confirms the result of coarse grain microstructure described above. Two types of microstructures, equiaxed grains and lamellar domains, are presented in the BFI (Fig. 8b), where the boundaries between them are clearly seen. One may take the advantage of this appearance to identify the NG layer and the EG layer. The observations on the FiE region outside RA suggest that a relatively lower level of local plastic deformation developed and the original coarse microstructure maintained in this region.

For the purpose of microstructure examination on the profile of crack initiation region for the case with positive stress ratio, a TEM sample B1-RA was cut by FIB from 

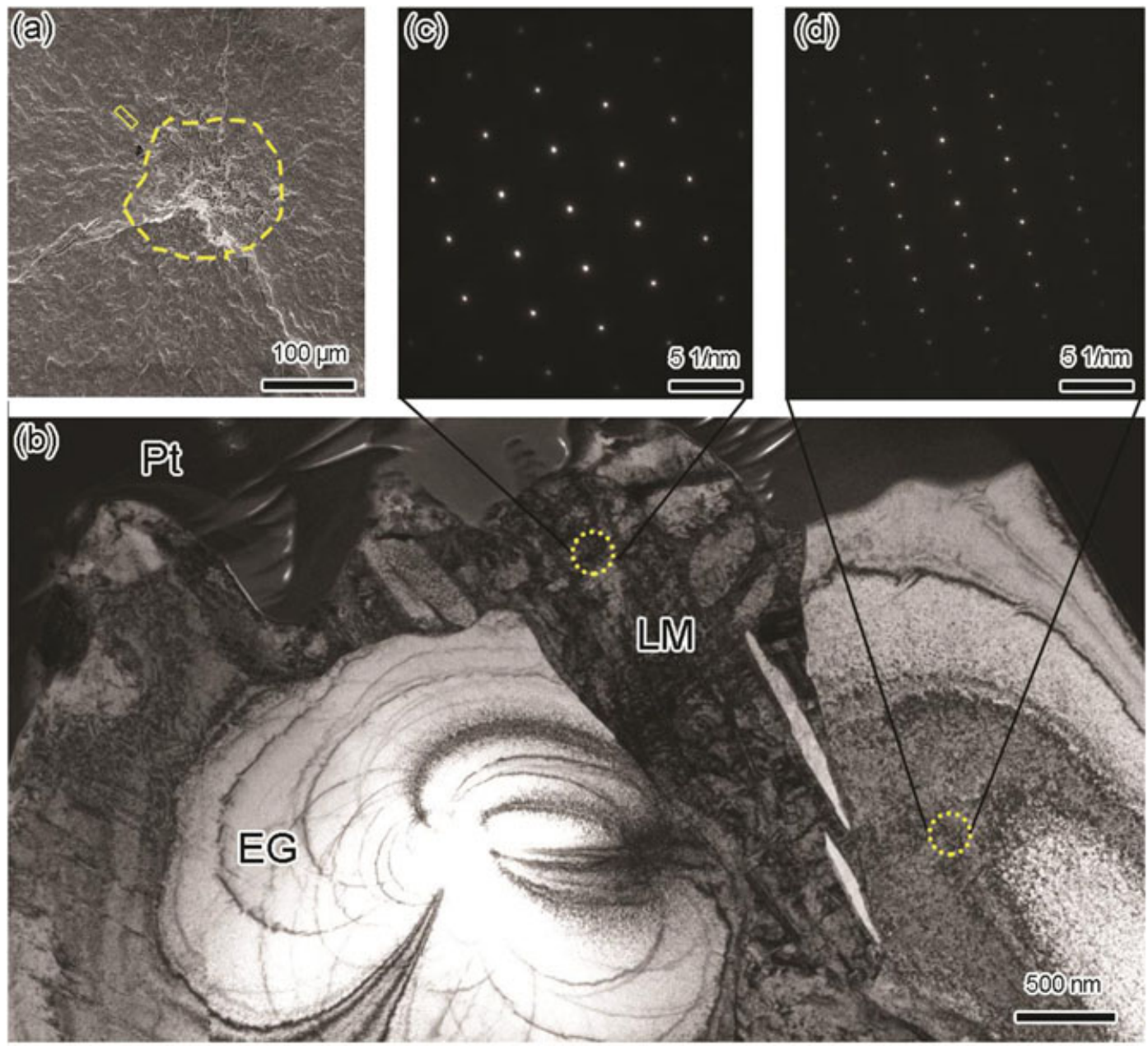

Fig. 8 SEM image, BFI and SAD patterns of FiE region (outside RA) for A1-FiE from counterpart fracture surface of Fig. 5: (a) SEM image showing crack origin and RA (dotted curve loop), marking rectangle being the TEM sample location, (b) BFI under FiE region outside RA, presenting Pt layer and coarse grain layer, (c) SAD pattern underneath the FiE surface, showing isolated spots, indicating just one grain within the diffraction area, and (d) SAD pattern away from the FiE surface, showing the single grain diffraction pattern. [Colour figure can be viewed at wileyonlinelibrary.com]

the fracture surface of Specimen B1 $(R=0.5)$ as shown in Fig. 9a. The BFI of Fig. 9b just shows the Pt protection layer and the coarse grain layer, and no evidence of nanograins has been observed. The $\mathrm{SAD}$ results underneath the RA surface (Fig. 9c) and away from the RA surface (Fig. 9d) show the pattern of isolated spots, which suggest that for the case of VHCF with positive stress ratio of $R=0.5$, the microstructure in the crack initiation region is without grain refinement but remains coarse grains.

From the two observations in this section (Figs 8 and 9) together with the two ones in the previous section (Figs 5 and 6), it is revealed that NG layer only formed in the RA for VHCF with negative stress ratio (A1-RA and A2-RA). For the cases of A1-RA and A2-RA, the formation of nanograins can be explained by NCP model, ${ }^{38}$ which regards that the formation of nanograins during the crack initiation of VHCF needs two conditions, that is, the compression loading that results in the contacting between crack surfaces, and the sufficient number of loading cycles that ensures the enough contacts between the crack surfaces, and this process is associated with the effect of crack closure and the relaxation of residual stress. ${ }^{38}$ The cases of A1-RA and A2-RA satisfy these two conditions, in which the microstructure underneath the crack surface fragmented into nanograins after a huge accumulation of cyclic pressing, with the assistance of residual stress relaxation and crack closure effect at each cycling. However, the number of loading cycles for A1-FiE (the fatigue life from the boundary of RA to that of FiE) seems not enough to cause sufficient local plastic deformation at crack surface region and to produce the NG layer in the FiE region outside RA. As to the case of B1-RA, it seems to be a lack of the necessary 

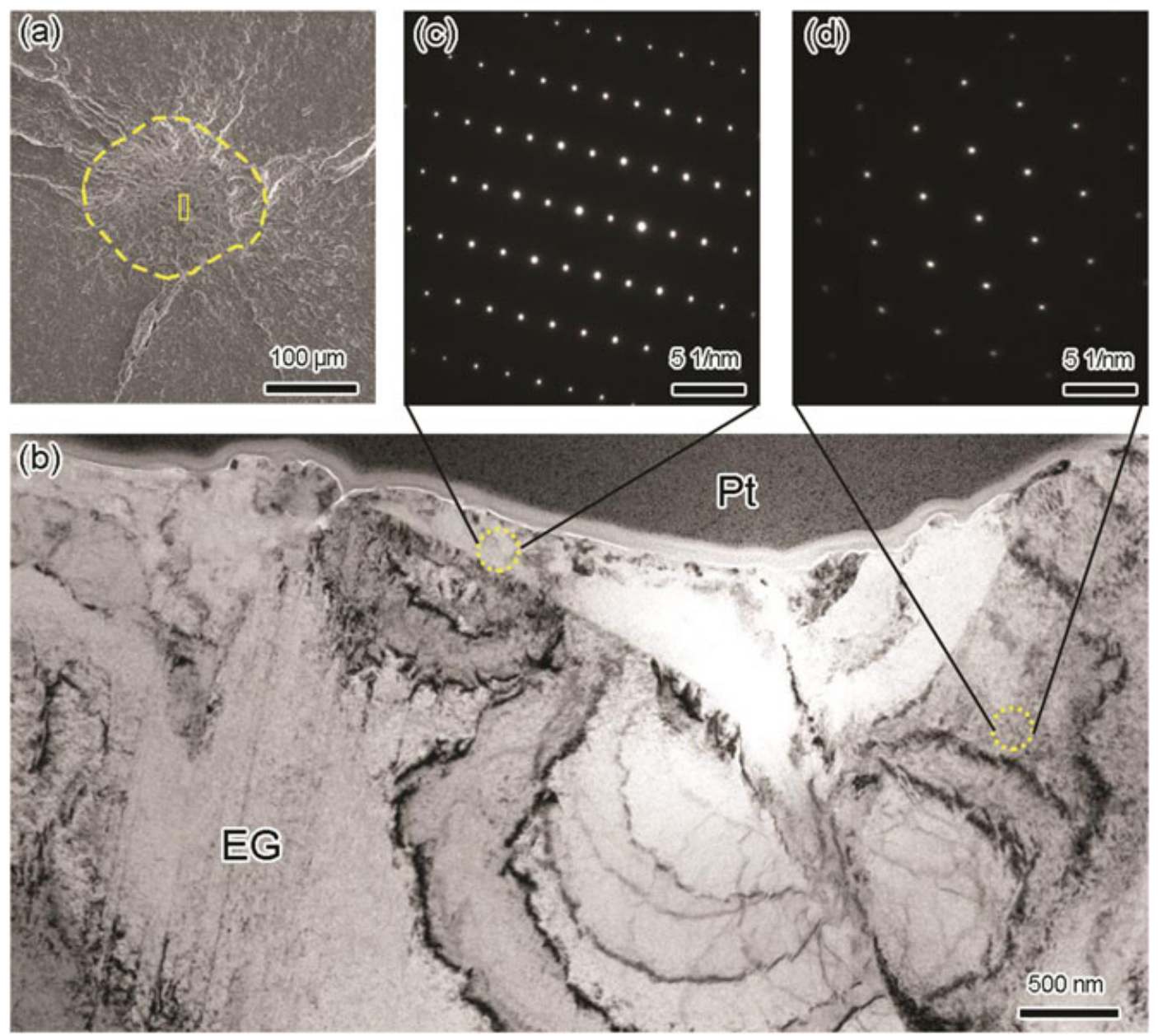

Fig. 9 BFI and associated SAD patterns of B1-RA: (a) RA (dotted curve loop) with $R=0.5, \sigma_{\mathrm{a}}=240 \mathrm{MPa}, N_{\mathrm{f}}=4.30 \times 10^{7}$, TEM sample location marked by a rectangle, (b) BFI showing microstructure underneath RA surface, (c) SAD pattern underneath the RA surface, showing isolated spots of a single grain, and (d) SAD pattern away from the RA surface showing isolated spots of a single grain. [Colour figure can be viewed at wileyonlinelibrary.com]

contacting between originated crack surfaces because of the state of positive stress ratio, such that the microstructure underneath the surfaces of crack initiation region cannot be refined in the crack initiation process. Thus, it is certain that the NCP process is the mechanism of nanograin formation for VHCF crack initiation for the titanium alloy. Nevertheless, it is worthwhile noting that for the titanium alloy, the RA region is formed because of cleavage facets from $\alpha$ grains, which happens in the cases of interior crack initiation for both positive and negative stress ratios. For the case of negative stress ratios, the contacts between crack surfaces prevail, which leads to the formation of NGs, whereas for the case of positive stress ratios, the RA region remains coarse grains with the presence of rough feature because of facet morphology.

The characteristics of FGA in VHCF of high-strength steels have been reported in detail by several researchers. ${ }^{34,35,38,46,47}$ However, for the VHCF of titanium alloys, the present paper is likely the first time to reveal the nature of nanograins in and only in the RA of fatigue crack initiation for the case of $R=-1$. The notch effect and the size effect on VHCF behavior for titanium alloys are also very important topics. A recent study has elaborated the influence of severely $\mathrm{V}$-notched feature of Ti-6Al-4V specimens under multiaxial loading conditions, ${ }^{48}$ which enlightens us about a further investigation of the microstructure evolution for VHCF with the two effects taken into account.

\section{Micro-damages in RA}

The crack initiation mechanism for VHCF of titanium alloys was because of the formation of micro-damages (facets), followed by the coalescence of the microdamages. ${ }^{25}$ Thus, it is reasonable to anticipate that isolated micro-damages may exist under RA surface. A longitudinal (profile) section sample in the center of RA 
was prepared by FIB from the counterpart fracture surface of Fig. 6a of Specimen A2 and the location of the sample is shown in Fig. 10a. This longitudinal (profile) section sample was observed by SEM with back scattered electron (BSE) imaging, and the image is presented in Fig. 10b. Micro-damages in the scale of microns are observed underneath the RA surface, which are randomly distributed close to the fracture surface. Similar results were also reported in recent papers. ${ }^{23,40}$

Micro-damages were also seen in A1-RA by TEM as shown in Fig. 11. HAADF was also used to observe the morphology. As a result, a number of micro-damages were found on the profile close to the crack surface (Fig. 11). The sizes of micro-damages range from tens of nanometers to hundreds of nanometers, which are smaller than those observed in the BSE image (Fig. 10). The different sizes of micro-damages suggest that the observed micro-damages are in different developmental stages and evolve with the increase of loading cycles.

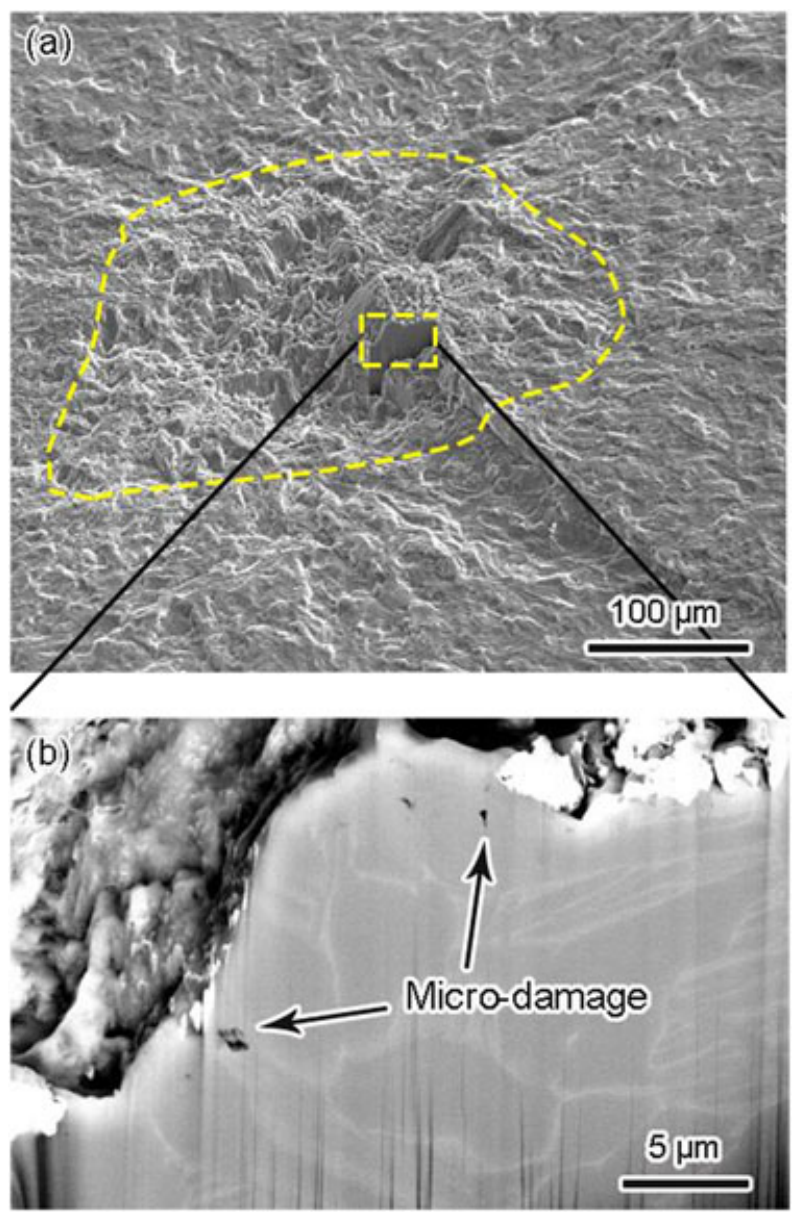

Fig. 10 Image of a longitudinal-section sample in the center of RA from specimen A2 (counterpart fracture surface of Fig. 6a), (a) location of the longitudinal-section sample, and (b) BSE image of the longitudinal-section sample. [Colour figure can be viewed at wileyonlinelibrary.com]
Both BSE and HAADF images demonstrate that the internal micro-damages during VHCF process really exist, which are the precursors of fatigue crack initiation. In fact, it is the coalescence of micro-damages that results in the fatigue crack initiation. ${ }^{26,40}$ The micro-damages shown in Figs 10 and 11 illustrate a clear evidence of fatigue crack precursor existence in spite of the absence of obvious coalescence between the micro-damages. It is interesting that the micro-damages coexist with the nanograins underneath the fracture surface of RA (e.g. A2-RA of Figs 6 and 11). However, it should be noted that the formation of micro-damages is before crack initiation and the formation of nanograins is after crack initiation. Thus, the NG layer appears just in the case of VHCF of negative stress ratio with sufficient loading cycles explained by the NCP mechanism. ${ }^{38}$ In contrary, the formation of micro-damages is regardless of loading type with different stress ratios, and is just the damage result because of a large number of loading cycles.

\section{Estimation of fatigue life and crack extension rate for RA}

As known, the process of crack extension for the case of interior crack initiation involves the stages of a crack formation (RA), its extension to FiE and finally the arrival at the position for fracture toughness. The value of $\Delta K_{\mathrm{RA}}$ is regarded as that of $\Delta K_{\mathrm{th}}$. In the following estimation, crack initiation region is treated as a pennytype crack. Here, Paris relation is considered valid to describe the crack growth after $\Delta K_{\mathrm{th}}$ :

$\frac{\mathrm{d} a}{\mathrm{~d} N}=A \Delta K^{m}$.

Then, Paris formula (Eq. (2)) is used to calculate the fatigue life from the boundary of RA to that of FiE $\left(N_{1}\right)$ and that from the boundary of FiE to the critical boundary defined by the fracture toughness of material $\left(N_{2}\right)$ through direct integration of Eq. (2). The equations for $N_{1}$ and $N_{2}$ are: ${ }^{29}$

$$
\begin{aligned}
& N_{1}=\frac{2}{(m-2) A Y^{m} \Delta \sigma^{m}}\left[\frac{1}{a_{\mathrm{RA}}^{(m-2) / 2}}-\frac{1}{a_{\mathrm{FiE}}^{(m-2) / 2}}\right] \\
& N_{2}=\frac{2}{(m-2) A Y^{m} \Delta \sigma^{m}}\left[\frac{1}{a_{\mathrm{FiE}}^{(m-2) / 2}}-\frac{1}{a_{K_{\mathrm{IC}}}^{(m-2) / 2}}\right]
\end{aligned}
$$

where $A$ and $m$ are the parameters in relation with the test material, with $A=1.0 \times 10^{-13}$ and $m=4.56$ obtained by fitting the crack growth data, and $Y$ is the related shape factor taken as $0.5 \sqrt{\pi}$. Further, the fatigue life for RA $\left(N_{\mathrm{i}}\right)$ is obtained by the total fatigue life $\left(N_{\mathrm{f}}\right)$ minus 


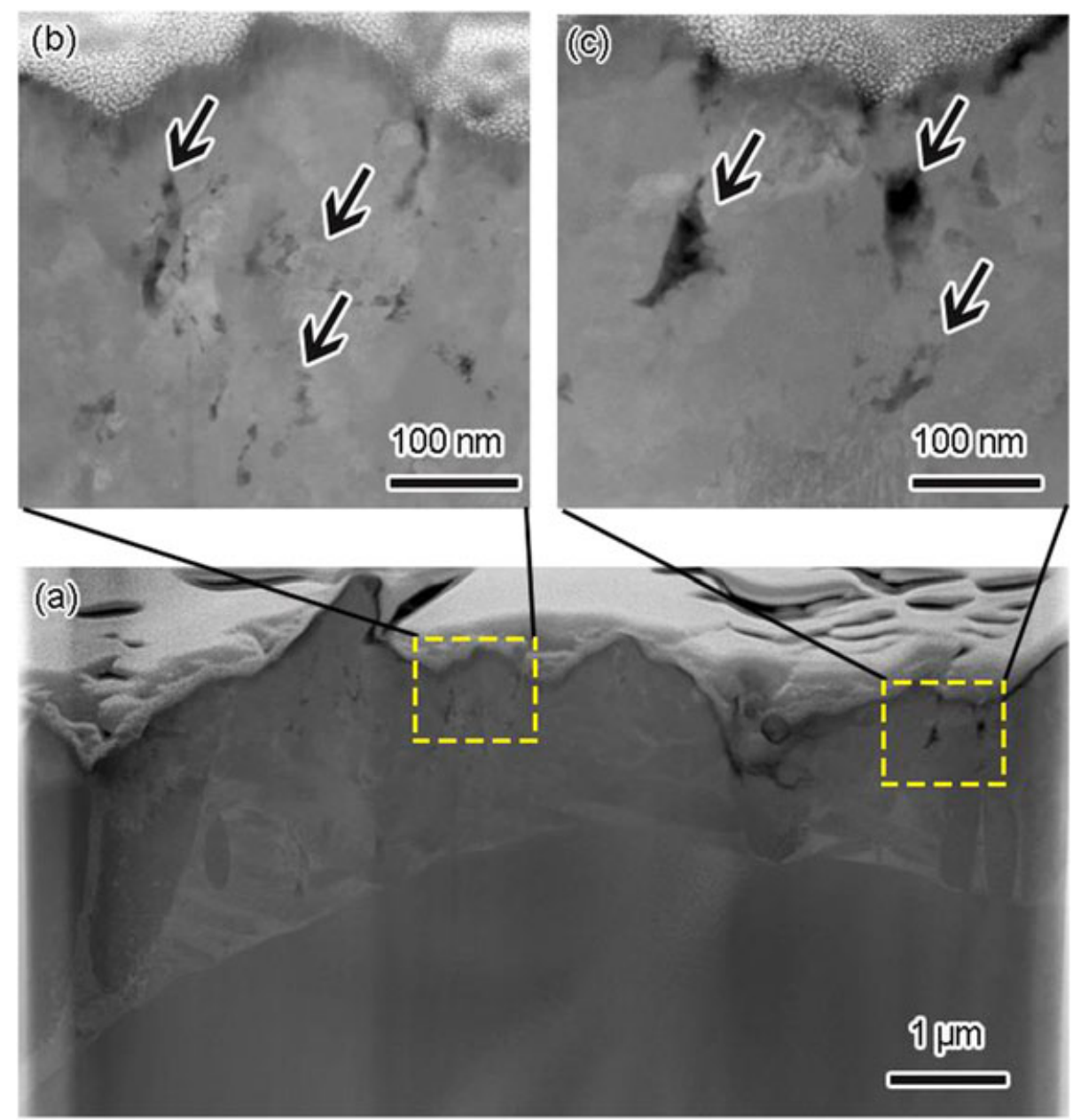

Fig. 11 HAADF images of the NG layer containing micro-damages of A1-RA, low magnification (a), and high magnification (b) and (c). [Colour figure can be viewed at wileyonlinelibrary.com]

Table 2 Results of da/dN within RA, and $N_{1}, N_{2}$ and $N_{\mathrm{i}}$ for specimens at tested stress ratio

\begin{tabular}{|c|c|c|c|c|c|}
\hline$R$ & $N_{\mathrm{f}}$ & $\begin{array}{l}N_{1}\left(N_{1} / N_{\mathrm{f}}\right) \\
a_{\mathrm{RA}} \text { to } a_{\mathrm{FiE}}\end{array}$ & $\begin{array}{l}N_{2}\left(N_{2} / N_{\mathrm{f}}\right) \\
a_{\mathrm{FiE}} \text { to } a_{\mathrm{KIC}}\end{array}$ & $\begin{array}{c}N_{\mathrm{i}} / N_{\mathrm{f}} \\
a<a_{\mathrm{RA}}\end{array}$ & $\begin{array}{c}\mathrm{d} a / \mathrm{d} N(\mathrm{~m} / \text { cycle }) \\
a<a_{\mathrm{RA}}\end{array}$ \\
\hline-1 & $1.8 \times 10^{9}$ & $9.5 \times 10^{5}(0.1 \%)$ & $1.2 \times 10^{5}(0.1 \%)$ & $99.8 \%$ & $1.4 \times 10^{-13}$ \\
\hline-1 & $4.5 \times 10^{7}$ & $8.6 \times 10^{5}(1.9 \%)$ & $5.5 \times 10^{4}(0.1 \%)$ & $98.0 \%$ & $3.1 \times 10^{-12}$ \\
\hline-0.1 & $1.8 \times 10^{7}$ & $1.9 \times 10^{5}(1.0 \%)$ & $2.9 \times 10^{4}(0.2 \%)$ & $98.8 \%$ & $7.0 \times 10^{-12}$ \\
\hline-0.1 & $3.8 \times 10^{7}$ & $1.1 \times 10^{5}(0.3 \%)$ & $6.5 \times 10^{4}(0.2 \%)$ & $99.5 \%$ & $4.5 \times 10^{-12}$ \\
\hline-0.1 & $3.1 \times 10^{7}$ & $2.2 \times 10^{5}(0.7 \%)$ & $2.0 \times 10^{4}(0.1 \%)$ & $99.2 \%$ & $5.2 \times 10^{-12}$ \\
\hline-0.1 & $1.2 \times 10^{8}$ & $2.3 \times 10^{5}(0.2 \%)$ & $5.6 \times 10^{4}(0.1 \%)$ & $99.7 \%$ & $1.5 \times 10^{-12}$ \\
\hline 0.1 & $1.2 \times 10^{7}$ & $2.8 \times 10^{5}(2.2 \%)$ & $1.6 \times 10^{4}(0.1 \%)$ & $97.7 \%$ & $9.6 \times 10^{-12}$ \\
\hline 0.1 & $2.0 \times 10^{7}$ & $2.7 \times 10^{5}(1.3 \%)$ & $1.7 \times 10^{4}(0.1 \%)$ & $98.6 \%$ & $7.4 \times 10^{-12}$ \\
\hline 0.1 & $6.3 \times 10^{6}$ & $2.3 \times 10^{5}(3.7 \%)$ & $1.5 \times 10^{4}(0.2 \%)$ & $96.1 \%$ & $2.5 \times 10^{-11}$ \\
\hline 0.1 & $2.3 \times 10^{7}$ & $1.8 \times 10^{5}(0.8 \%)$ & $6.5 \times 10^{4}(0.3 \%)$ & $98.9 \%$ & $8.2 \times 10^{-12}$ \\
\hline 0.1 & $2.4 \times 10^{8}$ & $2.6 \times 10^{5}(0.1 \%)$ & $1.2 \times 10^{5}(0.1 \%)$ & $99.8 \%$ & $8.7 \times 10^{-13}$ \\
\hline 0.1 & $1.5 \times 10^{7}$ & $2.5 \times 10^{5}(1.6 \%)$ & $6.9 \times 10^{4}(0.5 \%)$ & $97.9 \%$ & $1.2 \times 10^{-11}$ \\
\hline 0.1 & $1.2 \times 10^{7}$ & $3.6 \times 10^{5}(3.1 \%)$ & $4.6 \times 10^{4}(0.4 \%)$ & $96.5 \%$ & $1.4 \times 10^{-11}$ \\
\hline 0.1 & $4.3 \times 10^{7}$ & $6.4 \times 10^{5}(1.5 \%)$ & $9.1 \times 10^{4}(0.2 \%)$ & $98.3 \%$ & $4.4 \times 10^{-12}$ \\
\hline 0.1 & $2.8 \times 10^{7}$ & $5.5 \times 10^{5}(2.0 \%)$ & $1.2 \times 10^{5}(0.4 \%)$ & $97.6 \%$ & $7.2 \times 10^{-12}$ \\
\hline 0.5 & $4.3 \times 10^{7}$ & $1.5 \times 10^{6}(3.5 \%)$ & $1.1 \times 10^{5}(0.3 \%)$ & $96.2 \%$ & $3.4 \times 10^{-12}$ \\
\hline 0.5 & $1.5 \times 10^{7}$ & $9.8 \times 10^{5}(6.4 \%)$ & $2.6 \times 10^{5}(1.7 \%)$ & $91.9 \%$ & $2.0 \times 10^{-11}$ \\
\hline 0.5 & $1.8 \times 10^{8}$ & $1.0 \times 10^{6}(0.6 \%)$ & $5.2 \times 10^{5}(0.3 \%)$ & $99.1 \%$ & $1.9 \times 10^{-12}$ \\
\hline 0.5 & $5.2 \times 10^{8}$ & $1.1 \times 10^{6}(0.2 \%)$ & $3.9 \times 10^{5}(0.1 \%)$ & $99.7 \%$ & $7.5 \times 10^{-13}$ \\
\hline
\end{tabular}



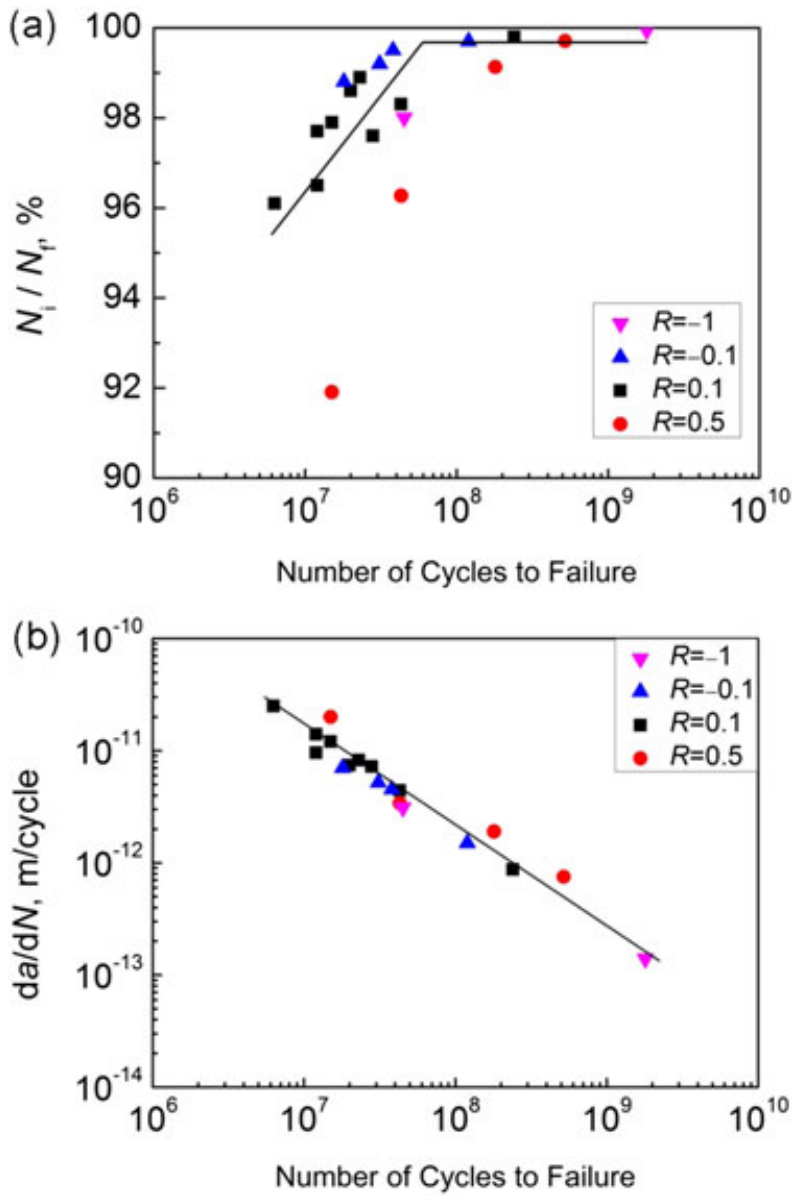

Fig. $12 N_{\mathrm{i}} / N_{\mathrm{f}}$ (a) and $\mathrm{d} a / \mathrm{d} N(\mathrm{~b})$ versus total fatigue life based on the data from Table 2. [Colour figure can be viewed at wileyonlinelibrary.com]

$N_{1}$ and $N_{2}\left(N_{\mathrm{i}}=N_{\mathrm{f}}-N_{1}-N_{2}\right)$ and the values of $N_{\mathrm{i}} / N_{\mathrm{f}}$ are readily calculated. It is noteworthy that the parameters $A$ and $m$ in Eq. (3) represent the cases in the Paris region. Equation (4) shares the same parameters with Eq. (3), which suggests that $N_{2}$ is overestimated. Thus, $N_{\mathrm{i}}$ is underestimated leading to a conservative result.

Table 2 lists the data of fatigue life $N_{1}, N_{2}$ and $N_{\mathrm{i}}$ for each specimen of the test cases with tested stress ratios. The result indicates that for 18 out of 19 points, the fatigue life contributed by the formation of RA $\left(N_{\mathrm{i}} / N_{\mathrm{f}}\right)$, that is, the crack initiation, is more than $96 \%$ of the total fatigue life. For a more explicit illustration, Fig. 12 presents the values of $N_{\mathrm{i}} / N_{\mathrm{f}}$ and $\mathrm{d} a / \mathrm{d} N$ versus the total fatigue life. Figure 12a indicates that, the values of $N_{\mathrm{i}} / N_{\mathrm{f}}$ for all data except one are between $96.1 \%$ and $99.9 \%$ with the trend of increasing with the increase of total fatigue life, and the exceptional datum point is outside the trend with $N_{\mathrm{i}} / N_{\mathrm{f}}=91.9 \%$. Figure $12 \mathrm{~b}$ indicates that, the values of crack extension rate in RA are of the orders of magnitude between $10^{-11}$ and $10^{-13}$ $\mathrm{m} /$ cycle with a trend of decreasing with the increase of total fatigue life. The results of Table 2 together with Fig. 12 confirm that the crack extension rate in crack initiation stage is extremely slow and the fatigue life consumed by crack initiation stage, that is, the formation of RA, is predominantly large for the titanium alloy, which emphasizes the importance for the investigation of crack initiation behavior for VHCF of titanium alloys.

\section{CONCLUSIONS}

This paper investigated the behavior of crack initiation and early propagation in the RA and FiE region for VHCF of a titanium alloy subjected to positive and negative stress ratios. The following conclusions are drawn.

1 The nature of RA for VHCF under $R=-1$ for the titanium alloy is a nanograin layer with the average grain size of $105 \mathrm{~nm}$ and the thickness of $800-1500 \mathrm{~nm}$. In FiE outside RA for VHCF under $R=-1$ and in RA for VHCF under $R=0.5$, the microstructure remains original coarse grains. This revelation affirms that a nanograin layer forms only in the characteristic region of crack initiation for the VHCF case under a negative stress ratio, which is explained by the process of contacting between both surfaces of an originated crack, that is, the NCP model.

2 Micro-damages in the scales from tens to thousands of nanometers prevail under the surface of crack initiation region regardless of cyclic condition of different stress ratios, which verifies that the micro-damages are the precursors of fatigue crack initiation.

3 For most cases of VHCF of the titanium alloy, the fatigue life consumed by the crack initiation stage, that is, in the characteristic region of RA, is larger than 96\% of total fatigue life. The crack extension rate within the characteristic region of RA is rather slow as between $10^{-11}$ and $10^{-13} \mathrm{~m} /$ cycle.

\section{Acknowledgements}

The authors appreciate the financial supports from the National Natural Science Foundation of China (11572325 and 11202210).

\section{REFERENCES}

1 Li, S. X. (2012) Effects of inclusions on very high cycle fatigue properties of high strength steels. Int. Mater. Rev., 57, 92-114.

2 Zimmermann, M. (2012) Diversity of damage evolution during cyclic loading at very high numbers of cycles. Int. Mater. Rev., 57, 73-91.

3 Mayer, H. (2016) Recent developments in ultrasonic fatigue. Fatigue Fract. Eng. Mater. Struct., 39, 3-29. 
4 Chai, G., Forsman, T., Gustavsson, F. and Wang, C. (2015) Formation of fine grained area in martensitic steel during very high cycle fatigue. Fatigue Fract. Eng. Mater. Struct., 38, $1315-1323$.

5 Sun, C., Liu, X. and Hong, Y. (2015) A two-parameter model to predict fatigue life of high-strength steels in a very high cycle fatigue regime. Acta Mech. Sinica, 31, 383-391.

6 Zerbst, U., Beretta, S., Köhler, G., Lawton, A., Vormwald, M., Beier, H., Klinger, C., Černý, I., Rudlin, J., Heckel, T. and Klingbeil, D. (2013) Safe life and damage tolerance aspects of railway axles-a review. Eng. Fract. Mech., 98, 214-271.

7 Fajkoš, R., Zima, R. and Strnadel, B. (2015) Fatigue limit of induction hardened railway axles. Fatigue Fract. Eng. Mater. Struct., 38, 1255-1264.

8 Pantelakis, S. and Tserpes, K. I. (2014) Adhesive bonding of composite aircraft structures: challenges and recent developments. Sci. China Phys. Mech. Astron., 57, 2-11.

9 Naito, T., Ueda, H. and Kikuchi, M. (1984) Fatigue behavior of carburized steel with internal oxides and nonmartensitic microstructure near the surface. Metall. Trans. A., 15, 1431-1436.

10 Neal, D. F. and Blenkinsop, P. A. (1976) Internal fatigue origins in $\alpha-\beta$ titanium allols. Acta Metall., 24, 59-63.

11 Pineau, A., Amine Benzerga, A. and Pardoen, T. (2015) Failure of metals III. Fracture and fatigue of nanostructured metallic materials. Acta Mater., 107, 508-544.

12 Pineau, A., McDowell, D. L., Busso, E. P. and Antolovich, S. D. (2015) Failure of metals I: Fatigue. Acta Mater., 107, 484-507.

13 Sakai, T., Sato, Y., Nagano, Y., Takeda, M. and Oguma, N. (2006) Effect of stress ratio on long life fatigue behavior of high carbon chromium bearing steel under axial loading. Int. 7 . Fatigue, 28, 1547-1554.

14 Shiozawa, K., Hasegawa, T., Kashiwagi, Y. and Lu, L. (2009) Very high cycle fatigue properties of bearing steel under axial loading condition. Int. 7. Fatigue, 31, 880-888.

15 Sun, C., Lei, Z. and Hong, Y. (2014) Effects of stress ratio on crack growth rate and fatigue strength for high cycle and very-high-cycle fatigue of metallic materials. Mech. Mater., 69, 227-236.

16 Zhao, A., Xie, J., Sun, C., Lei, Z. and Hong, Y. (2012) Effects of strength level and loading frequency on very-high-cycle fatigue behavior for a bearing steel. Int. 7. Fatigue, 38, 46-56.

17 Takeuchi, E., Furuya, Y., Nagashima, N. and Matsuoka, S. (2008) The effect of frequency on the giga-cycle fatigue properties of a Ti-6Al-4V alloy. Fatigue Fract. Eng. Mater. Struct., 31, 599-605.

18 Sun, C., Zhang, X., Liu, X. and Hong, Y. (2016) Effects of specimen size on fatigue life of metallic materials in high-cycle and very-high-cycle fatigue regimes. Fatigue Fract. Eng. Mater. Struct., 39, 770-779.

19 Paolino, D. S., Tridello, A., Chiandussi, G. and Rossetto, M. (2014) On specimen design for size effect evaluation in ultrasonic giga-cycle fatigue testing. Fatigue Fract. Eng. Mater. Struct., 37, 570-579.

20 Qian, G., Zhou, C. and Hong, Y. (2011) Experimental and theoretical investigation of environmental media on very-highcycle fatigue behavior for a structural steel. Acta Mater., 59, 1321-1327.

21 Qian, G., Zhou, C. and Hong, Y. (2015) A model to predict S-N curves for surface and subsurface crack initiations in different environmental media. Int. F. Fatigue, 71, 35-44.

22 Chandran, K. S. R. (2005) Duality of fatigue failures of materials caused by Poisson defect statistics of competing failure modes. Nat. Mater., 4, 303-308.
23 Heinz, S., Balle, F., Wagner, G. and Eifler, D. (2013) Analysis of fatigue properties and failure mechanisms of Ti6Al4V in the very high cycle fatigue regime using ultrasonic technology and 3D laser scanning vibrometry. Ultrasonics, 53, 1433-1440.

24 Liu, X., Sun, C. and Hong, Y. (2015) Effects of stress ratio on high-cycle and very-high-cycle fatigue behavior of a Ti-6Al4V alloy. Mater. Sci. Eng. A, 622, 228-235.

25 Liu, X., Sun, C., Zhou, Y. and Hong, Y. (2016) Effects of microstructure and stress ratio on high-cycle and very-high-cycle fatigue of Ti-6Al-4V alloy. Acta Metal. Sinica, 52, 923-930.

26 Liu, X., Sun, C. and Hong, Y. (2016) Faceted crack initiation characteristics for high-cycle and very-high-cycle fatigue of a titanium alloy under different stress ratios. Int. F. Fatigue, 92, 434-441.

27 Sakai, T. (2009) Review and prospects for current studies on very high cycle fatigue of metallic materials for machine structural use. F. Solid Mech. Mater. Eng., 3, 425-439.

28 Hong, Y., Zhao, A., Qian, G. and Zhou, C. (2012) Fatigue strength and crack initiation mechanism of very-high-cycle fatigue for low alloy steels. Metall. Mater. Trans. A, 43, 2753-2762.

29 Hong, Y., Lei, Z., Sun, C. and Zhao, A. (2014) Propensities of crack interior initiation and early growth for very-high-cycle fatigue of high strength steels. Int. F. Fatigue, 58, 144-151.

30 Tanaka, K. and Akiniwa, Y. (2002) Fatigue crack propagation behaviour derived from S-N data in very high cycle regime. Fatigue Fract. Eng. Mater. Struct., 25, 775-784.

31 Murakami, Y., Nomoto, T., Ueda, T. and Murakami, Y. (2000) On the mechanism of fatigue failure in the superlong life regime (N $>10^{7}$ cycles), Part II: a fractographic investigation. Fatigue Fract. Eng. Mater. Struct., 23, 903-910.

32 Murakami, Y., Nomoto, T., Ueda, T. and Murakami, Y. (2000) On the mechanism of fatigue failure in the superlong life regime ( $>10^{7}$ cycles), Part I: influence of hydrogen trapped by inclusions. Fatigue Fract. Eng. Mater. Struct., 23, 893-902.

33 Shiozawa, K., Morii, Y., Nishino, S. and Lu, L. (2006) Subsurface crack initiation and propagation mechanism in high strength steel in a very high cycle fatigue regime. Int. F. Fatigue, 28, 1521-1532.

34 Sakai, T., Oguma, N. and Morikawa, A. (2015) Microscopic and nanoscopic observations of metallurgical structures around inclusions at interior crack initiation site for a bearing steel in very high-cycle fatigue. Fatigue Fract. Eng. Mater. Struct., 38, 1305-1314.

35 Grad, P., Reuscher, B., Brodyanski, A., Kopnarski, M. and Kerscher, E. (2012) Mechanism of fatigue crack initiation and propagation in the very high cycle fatigue regime of highstrength steels. Scr. Mater., 67, 838-841.

36 Shanyavskiy, A. A. (2013) Mechanisms and modeling of subsurface fatigue cracking in metals. Eng. Fract. Mech., 110, 350-363.

37 Kovacs, S., Beck, T. and Singheiser, L. (2013) Influence of mean stresses on fatigue life and damage of a turbine blade steel in the VHCF-regime. Int. 7. Fatigue, 49, 90-99.

38 Hong, Y., Liu, X., Lei, Z. and Sun, C. (2016) The formation mechanism of characteristic region at crack initiation for veryhigh-cycle fatigue of high-strength steels. Int. 7. Fatigue, 89, $108-118$.

39 Oguma, H. and Nakamura, T. (2013) Fatigue crack propagation properties of $\mathrm{Ti}-6 \mathrm{Al}-4 \mathrm{~V}$ in vacuum environments. Int. 7 . Fatigue, 50, 89-93.

40 Heinz, S. and Eifler, D. (2016) Crack initiation mechanisms of $\mathrm{Ti} 6 \mathrm{Al} 4 \mathrm{~V}$ in the very high cycle fatigue regime. Int. F. Fatigue, 93, 301-308. 
41 Lei, Z., Xie, J., Sun, C. and Hong, Y. (2014) Effects of loading condition on very-high-cycle fatigue behaviour and dominant variable analysis. Sci. China Phys. Mech. Astron., 57, 74-82.

42 Zhao, A., Xie, J., Sun, C., Lei, Z. and Hong, Y. (2011) Prediction of threshold value for FGA formation. Mater. Sci. Eng. A, 528, 6872-6877.

43 Szczepanski, C. J., Jha, S. K., Larsen, J. M. and Jones, J. W. (2008) Microstructural Influences on Very-High-Cycle Fatigue-Crack Initiation in Ti-6246. Metall. Mater. Tran. A, 39, 2841-2851.

44 Zuo, J., Wang, Z. and Han, E. (2008) Effect of microstructure on ultra-high cycle fatigue behavior of Ti-6Al-4V. Mater. Sci. Eng. A, 473, 147-152.
45 Murakami, Y., Kodama, S. and Konuma, S. (1988) Quantitative evaluation of effect of nonmetallic inclusions on fatigue strength of high strength steel. Trans. Fpn. Soc. Mech. Eng., Part A, 54, 688-695.

46 Jiang, Q., Sun, C., Liu, X. and Hong, Y. (2016) Very-high-cycle fatigue behavior of a structural steel with and without induced surface defects. Int. F. Fatigue, 93, 352-362.

47 Spriestersbach, D., Brodyanski, A., Lösch, J., Kopnarski, M. and Kerscher, E. (2016) Very high cycle fatigue of bearing steels with artificial defects in vacuum. Mater. Sci. Tech., 32, 1111-1118.

48 Berto, F., Campagnolo, A. and Lazzarin, P. (2015) Fatigue strength of severely notched specimens made of Ti-6Al-4V under multiaxial loading. Fatigue Fract. Eng. Mater. Struct., 38, 503-517. 